\title{
THE ROLE OF CHANCES EQUALITY AND SOCIAL INCLUSION IN TERMS OF ECONOMIC DEVELOPMENT**
}

\author{
Iuliana Petronela GÂRDAN \\ Spiru Haret University, Faculty of Marketing and International Business \\ Email: geangupetronela@yahoo.com \\ Daniel Adrian GÂRDAN \\ Spiru Haret University, Faculty of Marketing and International Business \\ Email: danielgardan@yahoo.com
}

\begin{abstract}
The article deals with the issue of equality of chances, seen from the perspective of the importance that it may have in relation to social inclusion of individuals and economic development at the level of national economy. Social integration of both women and men is a natural goal, specific to the current level of economic, social and cultural development for most countries. The active promotion of equality of chances not only at the level of legislative initiatives but also in the space of social and entrepreneurial initiatives is the most effective solution to provide a favourable framework for the development of the contemporary society. The article reviews the concepts addressed, the legislation in Romania on equality of chances, and discusses the complex relationship that exists between sustainable economic development and the promotion of equality of chances on a large scale at the level of a national economy.
\end{abstract}

Keywords: chances equality, gender equality, social inclusion, sustainable development

JEL Classification: $\mathrm{F}_{63}, \mathrm{O}_{15}$

\section{Introduction}

The concept of equality of chances developed in the context of the social, cultural and economic transformations specific to the twentieth century. This concept is related to a number of other concepts, important in the context of promoting human rights and the modern principles regarding the economic and social development. Equality regarding the development opportunities related to

* This paper has been financially supported within the project entitled "Femei active pentru integritate şi responsabilitate (Active women for integrity and responsibility)", contract number POSDRU/144/6.3/S/134919, This project is co-financed by European Social Fund through Sectoral Operational Programme for Human Resources Development 2007-2013. Investing in people! Major Area of Intervation: 6.3 "Promoting equal opportunities on the labour market". 
education, equality before the law - these are themselves concepts that complement and interrelate with the equality of chances.

A specific issue of the equality of chances refers to the equality of gender the need for it to manifest in all sections of social and economic life. In social life, women and men are not given the same roles, they do not develop the same needs and interests. Needs, interests and roles will be influenced by membership in a particular social class, age, culture, religious orientation, political or economic system the individuals belong to.

Despite the stated differences, in a modern society, based on democratic principles, it is necessary for the equality of chances to emerge naturally, regardless of gender differences, all human beings having the right to develop their personal capabilities and choose to use the opportunities without being limited by the imposed roles, i.e., both women and men to have the freedom to fairly realize their aspirations, without a gender category to be advantaged over the other. Thus, promoting the concept of equality of chances entails eliminating the discrimination of any kind, the possibility that each member of the society to be able to freely use the human potential he/she holds.

\section{Review on the legislation on the equality of chances}

Promoting the principles specific to the equality of chances, to nondiscrimination, has been a constant in the legislative regulations developed in Europe. Through a number of normative acts, the EU has pursued the implementation of these principles at all the levels of the social, political and economic life of the Member States. Thus, the development of a legal framework designed to ensure the full participation of each person in the economic and social life without discrimination in terms of ethnicity, religion, sexual orientation or age was possible.

Along the time, the EU has adopted, ever since 1975, a series of directives on the application of some principles of equality targeting women and men. (www.mmuncii.ro) Thus, Directive No. 117 of 1975 stipulated the principle of equality in terms of remuneration, being followed in 1976 by Directive No. 207 on the principle of equal treatment between men and women as regards the access to employment, professional training and promotion, working conditions. Four years later, is adopted a new directive - No. 7 of 1979 stipulating the progressive implementation of the principle of equal treatment between men and women in the field of social security. Until 2000 , shall be successively regulated, through various directives a number of issues regarding equal treatment between men and women who perform independent activities, including agriculture, maternity protection, improving the safety and health at work of pregnant women or lactating women, parental leave, equality in the field of employment and of various aspects related to everyday life, equal treatment of persons without discrimination on racial and ethnic origin etc.

In 2007, the European Union has declared the European Year of Equal Opportunities for All, on this occasion being established the fulfilment of four 
objectives raising awareness on the right to equality and non-discrimination, stimulating the discussions on the means to stimulate the increase of participation within society of social groups representing potential victims of discrimination, recognizing the equality status and promoting a society based on a greater cohesion.

Furthermore, the European Union policy aimed at actively combating the stereotypes regarding the differences between men and women, changing behaviours, attitudes, norms and values that directly affect the human dignity.

In addition, a number of recent normative acts have regulated the equal access of women and men in the provision of goods and services, the establishment of community programs for employment and social solidarity, EU citizens' fundamental rights - rights that also stipulate the principles of equality of chances. In 2010, on the International Women's Day, the European Commission approved a document in the form of a commitment statement by which are also set out the principles of equality between women and men, principles that will govern the work of the Commission: (www.mmuncii.ro)

I. The principle of equal economic independence - promotes the idea of unrestricted access to professional affirmation and conditions for acquiring fair economic independence for women and men. Women are encouraged to reach their full potential through access to quality jobs and to balance work and family life.

II. The principle of equal pay for equal work and work of equal value - sets forth the need to reduce disparities between men and women in terms of remuneration (gaps in this respect are still recording at EU level - women are paid approximately $18 \%$ less than men per hour of performed work).

III. The principle of equality in decision-making - promotes the gender balance regarding the decision-making process from the political, economic life, the equitable representation of women alongside men in positions of power from the public life and economic activity, the promotion of women in positions with increased responsibility.

IV. The principle of respect for citizens' dignity, integrity and ending the gender-based violence - states the necessity of respecting the fundamental rights of female persons, seen as inalienable, integral and indivisible part of the universal human rights. It also promotes the complete ending of gender-based violence.

$\mathrm{V}$. The principle of promoting equality between women and men outside the European Union as well - sets forth the promotion of the concepts of equality of chances, gender equality at the level of all EU external policies, of the contacts and internationally signed partnerships.

In terms of the legislation governing the issue of equality of gender and chances, Romania has an adequate legal framework, which allows the protection of the vulnerable social groups and the active promotion of the principles of the equality of chances. Thus, in addition to EU regulations that are currently recognized and applied by the Romanian state in terms of EU membership, Romania benefited from a legislative opening corresponding to promoting the principle of equality of chances even before 1990. Subsequently, there were promulgated a series of normative acts such as: 
- Law No. 210 of 1999 on paternity leave

- Ordinance No. 137 of 2000 on preventing and sanctioning discrimination

- Law No. 202 on 2002, republished on equality of opportunity and treatment between women and men

- Law No. 53 of 2003 - The Labour Code, which regulates both the rights and obligations of employees in relation to employers without discrimination based on sexual orientation, age, etc.

- Law No. 217 of 2003 on combating and preventing domestic violence

- Government Decision No. 1054 of 8 September 2005 which states the regulation of organization and operation of county commissions and of Bucharest Municipality in the field of equal opportunities between women and men

- Government Decision No. 319 of 2006 on the National Strategy for equality of chances 2006-2009

- Emergency Ordinance No. 67 of 27 June 2007 on the application of the principle of equal treatment between men and women within the occupational social security scheme

- Emergency Ordinance No. 61 of 14 May 2008 on equal treatment between men and women in terms of access to goods and services and the supply of goods and services

- Government Decision No. 10 of January 9, 2013

\section{Equality of chances in terms of gender equality}

Gender segregation is still one of the serious problems that the society faces within the European Community. Women continue to bear various domestic responsibilities, regardless of the professional commitments of the job they have. Often women are engaged in occupations that have a flexible program or working hours, these being associated with the part-time program, which in its turn is associated with a lower salary.

In almost all the sectors of activity, women must face a gap in terms of wages, promotion opportunity and time thereof, the type of occupation in which they are engaged.

While there is a gap regarding wages in almost all fields, the jobs traditionally associated with men tend to be better paid than those traditionally associated with women, at least at the same level of requested competence. Even today, men and women tend to work in different jobs. This segregation of occupations is the main factor behind the gap that is to be found behind wages differences. Thus, in 2012, 53\% of the US civilian employees were represented by men and $47 \%$ by women. Almost $40 \%$ of these were employed in traditionally female professions (social occupations, nursing, teaching). By contrast, less than $5 \%$ of men were working in these fields. $45 \%$ of men were engaged in traditionally men activities such as computer programming, aerospace engineering, firefighters etc.), while only $6 \%$ of women had these kind of jobs. (AAUW, 2014)

In the last 40 years, a reduction of the gender segregation in terms of the occupations women have compared to men was managed. However, although more 40 
women had access to "traditionally male" occupations, the gap regarding the wages earned has maintained, for example a woman hired as a programmer is still on average paid less than her male counterpart.

Other studies confirm as well that, at European level, the trends regarding women's participation in the labour market are positive, if we analyse the statistics from 1994 to 2009. (Cipollone A., Patacchini E., Vallanti G., 2013, p. 21)

These statistics show that women's more active participation in the labour market is due to some complex factors of which we can mention the impact of individual characteristics of the labour offer for women, the differences present in the institutional framework on the labour market and of the social policy mix at the level of each country, the institutional changes oriented towards a model of flexicurity, the changes in the institutions that regulate the labour market and of the policy concerning this market at the level of each national economy.

The actions implemented in recent years in many countries of the EU and beyond, on the line of social protection and regulation policies have led to increasing the quality of employment opportunities available in the market, increasing the chances for disadvantaged people (including women) to re-enter the market workforce (facilitating re-employment rates), lower opportunity costs of employments (in relation to unemployment). The effects of these policies are different on categories of women depending on the type of family social support they receive, age and education level. Thus, the positive change of attitude towards the work done by women with children was favoured by the emergence and development of the types of part time jobs, for an indefinite period, which have not been seen anymore as "part-time" activities but as flexible ways of long term working and being paid. These positive effects were observed especially for women in an earlier stage of their professional life.

If the differences are maintained from the perspective of the gender, naturally the chances or possibilities of using the opportunities are endangered. We cannot talk about a real equality of chances if one way or another, different treatments or differentiations between the two genres manifest, both from the social and economic perspective - specific to the labour market.

The differentiations that apply to women come from the prejudices formed and transmitted in a particular cultural context, the stereotypes shared and transmitted as well in the same context. (Goudenhooft G., 2011, p. 23) In addition, these differences will correlate with certain forms of stigmatization as well.

Prejudices will be formulated and transmitted ideas within a social group, without having a real foundation, arguable and logic. Examples of such misconceptions related to gender differentiation are extremely well known, which also shows the degree to which they were propagated at the level of the collective mind (women are less intelligent than men, women are less able, women are not resistant to effort and stress etc.).

Stereotypes will represent repetitive and reproductive beliefs propagated in the collective mind. These are correlated to some extent with the preconceptions but represent a higher level of abstraction, with a much higher remanence over 
time, and individuals manifesting a greater resistance regarding the removal of such stereotypes from their own values and beliefs.

Gender stereotypes are present on a large scale in the culture specific to the nowadays societies, regardless of the country. In some countries, however, one can observe a stronger presence of these stereotypes, feed by the social or religious organization.

One of the most common gender stereotypes refers to the different social roles played by men, respectively women (man is seen as fulfilling productive roles leader, scientist, creator of culture, historian, etc.; while the woman fulfils reproductive roles - childbirth, raising and educating them, housekeeping, etc.).

These stereotypes are transmitted and augmented through education, through the interaction between individuals and, if they are part of the basic culture of the population in question, they become landmarks of behaviour and relationship once individuals will mature.

These behaviours, if all the members of the society accept them, cause a vicious cycle, individuals engaging in activities that reinforce the stereotypes. The influence of these gender stereotypes does not stop or is not limited to men women inter-human relationships, but they occur on the labour market, causing behaviours and phenomena that negatively affect the equality of chances of the two genders. First, a series of erroneous representations of the roles and attributions that men and women can have on the labour market is created. Second, stereotypes can create inferiority or superiority complexes as appropriate.

Although the legislative body, both internationally and particularly at European level, offers a multitude of normative acts governing the equal access to work regardless of gender, access to equal pay of the labour regardless of gender, access to similar working conditions regardless of gender, the issue of discrimination and of the existence of stereotyping requires a stronger involvement of the civil society, of the NGOs and associations that advocate for transparency and social equity.

Changing the perceptions and personal beliefs is a long process that involves learning from an early age the principles of non-discrimination and equality of chances. The education of children and youth should be done on both levels - both formally, through formal education systems and informally within the inter-family relationships. Only through a constant and consistent effort, this kind of misconceptions and stereotypes could be changed, creating the prerequisites for their real elimination from the collective mind.

\section{Equality of chances in terms of access to education}

Education is a complex process that is intended to provide members of the society the development and usage of their own intellectual and vocational potential at the highest possible levels. Equality of chances between genders in terms of access to education is a prerequisite for the actual social progress, for the affirmation of some democratic values. 
Access to education must be done free, unrestricted for different individuals and different social groups. This access should not be restricted by any barriers, the issue of equality in education was seen in terms of the effort to divide the educational resources so that they be used rationally and correctly by all members of the society. (Lynch K., Baker J., 2005, p. 134)

The issue of the access to education can be analysed from the perspective of five essential factors that influence the effective access: equality in terms of resources, access to respect and recognition, care, love and solidarity, strength.

Access to education is closely correlated within society to the possession of the necessary economic resources. Deprivation of economic resources prevents the access to the same forms of education, subsequently, the cultural capital offered by the education institutions turning into economic capital. An individual who does not have access to economic resources cannot reach the highest levels of education and thus cannot acquire cultural capital, which he can later turn into economic capital. If gender inequalities are deep and are highlighted on the labour market, this can affect the family incomes and automatically can lead to situations in which children will not have an unrestricted access to higher forms of education.

The elimination of the serious economic disparities and state's intervention by ensuring a free access to the basic educational services can provide the solutions to the first cause of the inequalities in education - access to resources.

A second important aspect in managing the equality in education is represented by the provision in equidistant terms of respect and recognition. Some educational systems do not offer the possibility to recognize diversity. Thus, different treatments may appear depending on criteria regarding gender, religion, class, race, ethnicity, age, etc.

These treatments are materialized in different educational programs, different teaching styles. From the perspective of gender inequalities, these can manifest in the educational field as well, starting with the lack of attention paid in the class up to the unequal stimulation of the personal intelligence of children with gender differentiations.

The solutions to these serious phenomena are given by the powerful intervention of both state's institutions authorized to organize educational systems and civil society through its representatives. Implementing online educational systems, based on e-learning can also be a useful way to eliminate difficulties regarding access to education of some disadvantaged social groups. The e-learning systems can eliminate obstacles related with space, time and working hours for broad social categories. (Ionescu E.I., Oprea C.C., 2011, p. 404) Educating children and young people, as well as the promotion among teachers of the ideas regarding the acceptance of cultural and gender diversity is the basis for solving these situations

\section{The relationship between equality of chances and social inclusion}

The issue of promoting the equality of chances is closely correlated with that of social inclusion. Social inclusion is a concept that gives the measure of the degree of social cohesion and application of democratic principles in a state; it 
guarantees the right of all members of the society to actively participate in its life, to assume social roles in full accordance with their own abilities, training level, personality and interests.

The promotion of a proper social inclusion cannot be made without first obtaining an equality of chances. In order for individuals to be able to socially include in a coherent manner, the essential condition is represented by the possibility to enjoy equal opportunities for development, for equal chances to use their own potential.

In addition, the social inclusion also refers to acknowledging the right of inclusion in the decision-making processes and not just enjoying their effects. (Ruth L., 2003, p. 7) Individuals must be able as well to express their will and interests in terms of the decisions that are taken at the level of social groups. Thus, social inclusion will refer to the active participation within groups, to the development of each ones potential. The concept of social inclusion as well as that of exclusion represents multidimensional concepts that do not refer, in a limited horizon, only to poverty and inequality. Social inclusion and equality of chances will potentiate each other.

Thus, as individuals enjoy equal chances, personal development and the affirmation of their own potential are stimulated. Once the individual is freely and unrestrictedly using his potential at a maximum level, the chances to successfully integrate into society grow proportionally. Once socially integrated, the optimal relationship with other members of the society, the active participation to the control and decision mechanisms ensures the individual increased possibilities to use the resources and the potential.

\section{The role of equality of chances in terms of sustainable economic development}

Equality of chances, poverty eradication and sustainable development are concepts that are intrinsically linked. Sustainable development takes into account multiple aspects of economic, social, environmental, political, etc. nature. The analysis of sustainable development starts however form the society's most important cells - the individuals. The way in which each member of the society puts himself forward, the participation in the social mechanism of the exchange actually determines the development potential and, automatically, the society's ability to implement sustainable development.

The manifestation of equality of chances, non-discrimination based on gender, allows all individuals within society to express their human potential in line with their own resources, capabilities and interests. Non-discrimination of women becomes a crucial element in the context in which woman's social role is highlighted by the amount of skills and characteristics she has accumulated so far. Thus, women have an active role in the economy, as economic and social agents, structurally being closer to the model of some real agents of sustainability.

Studies have shown that women are more likely than men to choose a lifestyle characterized by sustainability, to develop an environmentally friendly 
consumer behaviour and to take sustainable decisions. (United Nations Development Program, 2012, p. 12) Therefore, it is essential to ensure a strong participation of women in key leadership positions from the perspective of the decision-makers who can implement the sustainable development process.

A sustainable economy model will enable women to become active in positions of producers, managers, sellers, promoters of sustainable business. From the position of entrepreneurs, women can more easily achieve the transition to a sustainable economy, getting involved in the environmental protection or the "green industries". The involvement of the economic agents from the level of the national economy must be complete in order to be able to talk about substantial changes towards sustainable development. That is why entrepreneurial initiatives that are built on these models should be encouraged. With a ratio of almost $25 \%$ of all small and medium enterprises in developing countries, the entrepreneurial initiatives led by women can make a difference if we talk about a real commitment towards sustainable development.

From the institutional and legal point of view, sustainable development requires the creation of the necessary framework and institutions to ensure the effective implementation of its specific principles. This legal framework should be complemented by elements specific to promoting the equality of chances, as the manifestation of human creative potential cannot be realized without a regulatory framework that guarantees its use in conditions of fairness and security. All social categories and existing groups should be able to have access to institutional resources used to implement sustainable development.

In terms of the policies and actions regarding the regulation of the global energetic system, a more active participation of women at the decision-making level, to the substantiation of the energy policy strategies is required.

The optimal representation of women within the analysis, implementation and decision groups represents another prerequisite for stimulating the sustainable development. The current lack of representativeness does not provide a healthy foundation for the decision-making progress concerning the sustainable development policies, both at the national economies levels and at the global one.

Sustainable development requires the engagement and the activity of a substantial number of change agents. Women, due to their intrinsic characteristics, represent potential change agents towards promoting the principles that lie behind sustainable development.

\section{Conclusions and future research directions}

The issue of efficiently promoting the equality of chances and social inclusion raises a number of question marks. Although in the last 40 years impressive efforts have been made at the level of regional and global institutions towards eliminating or alleviating the differences based on gender, race, religion, etc., relevant studies and analysis still indicate the existence of multiple gaps and of some differentiated approaches regarding the integration of individuals into the contemporary social and economic circuit. 
There still are states and national economies where gender segregation or on religious grounds is present. There are still cultural stereotypes that promote the most diverse differences between genders, different social roles of men compared to women. In addition, visible disparity between the pay of men compared to women or differences in access to certain types of occupations still occur on the labour market, in different regions of the world. Even at the level of education systems, there are still discriminatory approaches for social groups considered peripheral, prejudices or artificial communication barriers.

All these elements paint a complex economic and social reality, characterized by dynamism and huge potential for change and evolution. The more and more powerful affirmation of women in the economic and social life, the active and interchangeable roles in the family structure, the involvement in the political or economic decision represent elements that support the development potential in the direction of equality of chances affirmation.

We believe that one of the extremely important lines of action, perhaps even decisive for the future, is represented by the stimulation of children and youth's education towards being aware of the need for equality of chances and social optimum in terms of the social inclusion of the individuals. The moment when opinion leaders of tomorrow will form, from a very early stage, a coherent vision, lacking inherited stereotypes and preconceptions, on the issue of equality of chances, of recognising the natural differences, imposed by the impartial social roles which men and women can take in order to build the social good, all the efforts made so far towards humanity's evolution and social progress will find their justification and the real basis for tangible results.

\section{References}

AAUW, The simple truth about the gender pay gap, Washington, 2014, pp. 1-25, http://www.aauw.org/files/2014/03/The-Simple-Truth.pdf.

Cipollone A., Patacchini E., Vallanti G., Women labour market participation in Europe: Novel evidence on trends and shaping factors, IZA Discussion Paper No. 7710, October 2013, p. 1-39, http://www.siecon.org/online/wp-content/uploads/2013/09/ Cipollone-Patacchini-Vallanti.pdf.

Comisia Europeană, Comunicare a Comisiei către Parlamentul European, Consiliu, Comitetul Economic şi Social European şi Comitetul Regiunilor, Strategie pentru egalitatea intre femei şi bărbați, 2010-2015, Bruxelles, 2010, p. 2-14, http://www.mmuncii.ro/pub/imagemanager/images/file/Domenii/Egalitate\%20de\%2

0sanse/Strategia\%20UE\%20pentru\%20egalitatea\%20intre\%20femei\%20si\%20barba ti\%20\%202010-2015.pdf.

Goudenhooft G., The Influence of European Law Concerning Gender Discrimination in Romanian Labour Market: Some Aspects of Women's Migration in the EU, Journal of Identity \& Migration Studies, vol. 5, no. 1, 2011, pp. 21-36.

Ionescu E.I., Oprea C.C., Use of information technologies in education e-learning system, Conference proceedings of "eLearning and Software for Education" (eLSE), issue 01, 2011, pp. 403-406.

Lynch K., Baker J., Equality in Education: an Equality Condition Perspective, Theory and Research in Education, vol. 3, no. 2, 2005, pp. 131-164. 
Ruth L., The idea of social inclusion, Social Inclusion Research Conference, University of Bristol, 12 July 2003, http://socialpolicyframework.alberta.ca/files/documents/ 2003_social_inclusion_research_conference.pdf.

United Nations Development Program, Powerful synergies - Gender Equality, Economic Development and Environmental Sustainability, 2012, http://www.undp.org/ content/undp/en/home/librarypage/womens-empowerment/powerful-synergies/.

http://www.mmuncii.ro/j33/index.php/ro/2014-domenii/egalitate-de-sanse-intre-femei-sibarbati/1005-council-of-europe-gender-mainstraming. 
